Brit. J. industr. Med., 1954, 11, 110.

\title{
AN INDUSTRIAL HEALTH SERVICE IN NORWAY*
}

\author{
BY \\ HAAKON NATVIG \\ From the Institute of Hygiene, University of Oslo
}

Norway has an area of approximately 320,000 square kilometres, with a population of only about 3.2 millions. About $30 \%$ of the population live in the cities, whereas $20 \%$ live in suburban and industrial areas and other population centres, and the remaining $50 \%$ in rural areas.

The main occupations in Norway are agriculture and forestry, fishing and whaling, manufacturing and trade, as well as business and transport. During the years preceding and following the last world war Norway has been increasingly industrialized. Thus, the census of 1946 revealed that those employed in manufacturing and trade constituted the largest occupational group, with a total of 480,000 persons, 80,000 of whom were women.

The most important industrial enterprises are the iron and metal industry, the food industry, the pulp and paper industry, the textile industry, the chemical and electro-chemical industry, and mining.

Most industrial and manufacturing concerns are small, employing between 20 and 100 workers. A small number of industrial firms (about 600) have more than 100 employees, and only about 100 firms have a staff of more than 500 workers.

As industry has developed, the increasing problems of occupational hygiene and medical care called for the establishment of an industrial health service, with the following aims : (1) regular health control through periodical medical examinations, to protect and promote the health of the workers and other employees of industrial and other concerns ; (2) to promote industrial hygiene.

The former professor of hygiene at the University of Oslo, Carl Schioetz, was the pioneer in this work. In 1917 he tried to apply the principles mentioned above as a works doctor. Inspired by him and encouraged by his results, a few physicians interested in hygiene and occupational hygiene accepted in 1939 similar positions in other concerns. However, the work was still done on an experimental basis

\footnotetext{
* Based on a lecture given at WHO's first European seminar on occupational health at Leyden in 1952.
}

without a regular plan, and could therefore be of only limited value. During the years of World War II an increasing number of firms wished to employ works doctors, and so some of the physicians interested in hygiene got together to discuss what could be done.

They formulated the objectives of the industrial health service, both with regard to health control and to hygiene. The various aspects of the practical work were framed, including the design of a health card and regulations concerning the employment and salary of the physicians, with the purpose of creating a national uniform standard. The Norwegian industrial health service is based mainly upon the work of this group. The proposals which had been worked out during the years 1943 to 1945 were tested by a few practising physicians with good results. By the end of the war the plan of an industrial health service was wholeheartedly approved by the Norwegian Medical Association.

In addition to the approval of the physicians and their organizations, the plan needed the sanction and cooperation of the employers and employees.

Negotiations with the chief organizations of the employers and workers were started, when the general plan of the original committee was introduced and subsequently accepted with a few minor modifications. Furthermore, the two organizations expressed their desire to establish a council together with the Norwegian Medical Association. Thus the Board of the Industrial Health Service was established in the spring of 1946.

\section{Organization}

The Norwegian Industrial Health Service is not based upon legislation but on a voluntary mutual agreement between the three parties concerned, viz., the Norwegian Medical Association, the Norwegian Employers' Association, and the Norwegian Federation of Labour. The activities of this service are coordinated and administered by the Board of the Industrial Health Service, a tripartite administrative 
council. The activities of this council include the propagation of information about the industrial health service and the keeping of records of all the cooperating industrial concerns. It also directs the application of the plans according to the principles agreed upon, and gives counsel and advice on questions concerning the industrial health service.

The board has a permanent office, jointly financed by the three participating organizations. Individual firms may choose whether or not they wish to have a medical service in their plant. If participation is desired, the firm is required to comply with the policies of the board.

\section{The General Plan}

The general plan of the industrial health service calls for the establishment of a medical office with the necessary equipment and a waiting room at the plant, and the employment of doctors and nurses to carry out the work according to the adopted policies.

\section{Expenses}

All expenses connected with the plant health service, such as equipment, the surgery, remuneration of the physician and nurse, maintenance, etc., are met by the plant.

The cooperating industrial firms are also required to provide facilities for laboratory analysis at the plant. Great importance is attached to such an arrangement, not only to keep the industrial health service separated from general medical practice, but also because we want the physicians to be established at the plant. Only then can contact be maintained between the physicians, the management, and the workers, and only then can the physician devote himself fully to his work.

\section{Working Hours of the Works Doctor}

The working hours are stipulated by the Board of the Industrial Health Service according to the nature of the industry and the number of manual and clerical workers employed. In commercial firms and other firms without special problems of occupational hygiene, working hours have been fixed at one hour per week per 100 workers or less, and in industrial firms with special problems of occupational hygiene to two hours per week per 100 workers or less.

\section{Salaries}

The industrial medical officer is paid for his in-plant service per hour according to an adopted wage scale. Both working hours and other condi- tions must be approved by the Board of the Industrial Health Service in accordance with a standard contract.

\section{Employment of Works Doctors}

The following rules apply to the employment of works doctors in Norway: (1) Posts are advertised in accordance with conditions approved by the Board of the Industrial Health Service, and the Director General of Public Health nominates the three applicants considered best qualified, or (2) enquiries are made to the Board of the Industrial Health Service concerning its recommendation of candidates considered for employment by the firm before a definite choice is made.

All positions advertised shall be occupied only upon nomination. During the last five years $88 \%$ of the industrial firms introducing an industrial health service have employed works physicians according to the first plan whereas only $12 \%$ have used the second alternative.

The works physician is subordinated to the manager or other administrative head. The current employment policies are designed to offer the works physician adequate independence in his work. Most physicians are employed on a competitive basis and their duties and rights are clearly defined in printed instructions. These are known by the management and the staff alike. Norwegian works physicians therefore do not have the impression of " being bought and paid" by the employers. They have a free and independent position which allows them to retain an objective attitude towards both employers and workers.

\section{Duties of the Works Physician}

The works physician shall supervise the health of the employees by means of preventive medical examinations, health information, and other preventive measures. He shall examine all who are accepted for employment at the plant, and shall give a report to the management about their fitness for the work. Further, he shall regularly-preferably once a year-examine all employees at the plant.

Young workers, persons engaged in work dangerous to health, employees with partial disability resulting from disease or other causes, and persons frequently absent because of illness, receive special attention.

Standardized health cards and other forms are used for medical examinations.

It was realized that it would be of primary importance to make the medical examinations as 
extensive and efficient as possible. This is assured as far as possible by using objective methods of examination and standardized health cards and other forms. It is emphasized that health control should not primarily include the negative aspects of the industrial health service, i.e., the detection of disease. The positive aspects, i.e., health information and prophylactic health care, are just as important. Great importance is attached to anamnestic data in connexion with the medical examinations, such as previous illness, family history, environmental situation, travel facilities, habits, hobbies, problems of personal and social adjustment.

By pre-employment examinations the works physician shall assist in determining the kind of work which is most suitable for each applicant on the basis of his physical and mental qualifications. In other words, he shall point out the abilities of the applicant rather than his disabilities. Many partly disabled have thus been helped to find suitable employment in industry.

Our original plan was to have all workers medically examined preferably once a year. We are now inclined to relax our previous standard for those between the ages of 20 and 40 years who do not present any sign of disease or special health problem at the initial examination. A medical examination every other or maybe every third year is now considered sufficient for this group. On the other hand all young workers and those partly disabled or with a weak constitution, as well as workers exposed to industrial health hazards, should be examined annually or at more frequent intervals. However, any employee has the opportunity of consulting the works physician at any time. All examinations shall take place during working hours without loss of wages.

Because it is not possible to carry out an effective programme of health control without a knowledge of the state of health of each worker during intervals between examinations, a special system of sickness absence reports has been introduced. In each case of sickness absence of more than three days' duration a confidential report about the disease, the length of absence, and the physician consulted shall be submitted to the works physician by the worker upon his return to work. This information is then recorded on the worker's health card so that the physician at all times may be kept informed about the state of health of the individual worker. In addition, these reports give a reliable picture of the nature and extent of diseases among the workers and in the plant as a whole. It is evident that this registration of sickness absences also yields valuable information in the field of occupational hygiene.
The works physician shall also be the works hygienist. He shall supervise the hygienic conditions in the plant by means of inspections. Furthermore, he shall investigate complaints about hygienic deficiencies, seek to prevent occupational diseases and accidents, as well as other industrial hazards, and work actively to promote hygiene and better working conditions in the plant.

Many works physicians have stimulated the management to establish a so-called health and safety board. The composition of these boards varies. Members are usually the works physician, one representative from the management, one from the manual workers, one from the other employees, one from the foremen, together with the safety engineer and the personnel manager. Through the activities of this health and safety board the hygienic conditions may be inspected and thoroughly studied. Complaints may be objectively investigated and recommendations for hygienic improvements presented to the management.

The works physician shall be the works consultant on medical hygiene. He shall serve as a consultant to the management, the foremen, and the production committee, and give advice in matters of sick-leave, transfer to other work, adaptation of the work on medical grounds, and other questions of a medicohygienic nature.

This part of the work has been a great help to management, which is increasingly appreciative of medical advice on questions of employment, personnel administration, sick-leave, pensions etc.

In cooperation with the industrial management and the supervisors, the works physician shall seek to combat absences due to malingering among the employees. He has the right to examine anyone suspected of malingering, and should by educational and informative means discourage abuse and, if needed, give warnings. The management, the supervisors, and the physician consulted shall be notified in cases of serious abuse of sickness absence or leave.

To facilitate the control of sickness absence, a system of individual registration of absence due to sickness or other causes has been introduced. Each absence is recorded in one of three groups : sickness absence, granted leave, or "shirking". The individual records thus give a revealing picture of the health and working capacity of each employee, enabling the works physician to carry out an efficient control of the workers in the specified points. The records give an annual cumulative survey of the total absence in the plant and of the distribution of absence in the various departments and groups of workers. Frequencies of absence may 
thus be compared within the plant and with comparable figures from other plants.

Like other physicians, the works physician is under the oath of secrecy. Information about the nature of disease in any employee must not be given to the management or to fellow workers without the consent of the individual concerned. The health cards and other information about the employees shall be locked up and be accessible only to the works physician and his staff who are also under the oath of secrecy.

The works physicians shall carry out their work in cooperation with private practitioners. Persons needing medical attention who have their own private doctor should be referred to him. The patient may also be referred directly to a specialist when required. In such cases the physician regularly consulted by the patient should always be informed about the results of the special examination.

It is a general agreement that the works physician shall not give regular medical treatment in his works surgery. But he may and should treat injuries and other conditions requiring immediate attention ; he may also give attention to occupational diseases not involving loss of work, and minor ailments, which may be treated instantly. No payment from the patient, the plant, or medical insurance is to be received for treatment in such instances.

There are two reasons for the adoption of this policy : the first is in the interest of the private practitioners ; the second concerns the scope of the industrial health service. We have been very anxious to ensure that physicians shall devote their time to preventive medical examinations and health guidance, as well as to hygienic work in the plant.

Another duty of the works physician is the preparation of an annual report to the industrial management. One copy is submitted to the Board of the Industrial Health Service and contributes to a broad evaluation of the efficiency of the industrial health service.

The purpose of this report is primarily to stimulate the works physicians to acquaint themselves with the problems of their respective industries and to study the effects of their work. The second purpose is to collect information in the field of industrial hygiene.

The Norwegian Industrial Medical Association has prepared a standard for annual industrial health service reports to facilitate statistical studies. The current standard report has three parts.

The first part is a general survey of the hygienic conditions in the plant as a whole, with information about the nature of the work and the personnel, and a report of the general medical examinations.
The second part includes the results of the individual tests which form part of the medical examination, such as tuberculin tests, B.C.G. vaccination, haemoglobin and blood pressure determinations, measurements of weight, serological tests.

The third part is devoted to statistics of absence. The report shows the absence among manual and clerical workers, men and women, and the various age groups respectively. A report of absence due to various diseases according to a specified grouping is also included in this part, together with a report of occupational diseases and accidents, granted leaves, and " shirking ". These reports are forwarded to the Board of Industrial Health, where they are included in national statistics.

\section{Experience of the Service}

As this industrial health service has existed for nearly a decade it seems to be worth while to summarize some of the experience gained during this period.

The policies which have been followed up to the present seem to be well suited to national conditions. Health authorities, the physicians, the employers, and the employees have supported the plan with very few exceptions. Indeed, no other social or hygienic scheme can demonstrate a similar rapid expansion and development.

DEVELOPMENT OF THE INDUSTRIAL HEALTH SERVICE IN NORWAY 1944-1951

\begin{tabular}{c|c|c}
\hline Date & Participating Plants & Workers Included \\
\hline Before 1944 & 32 & Approx. 12,800 \\
1944 & 46 & 14,315 \\
1945 & 63 & 20,321 \\
1946 & 100 & 39,678 \\
1947 & 263 & 74,554 \\
1948 & 375 & 99,616 \\
1949 & 435 & 125,339 \\
1950 & 498 & 141,502 \\
1951 & 542 & 167,687 \\
1952 & 572 & 176,164 \\
1953 & 653 & 186,490 \\
\hline
\end{tabular}

Our industrial health service has also stimulated and formed a pattern for the expansion of public health care to other population groups, such as housewives and students.

There are many reasons for this rapid development. It is evident that the social consciousness and spirit of cooperation prevalent during World War II and the initial post-war period and the subsequent rise in industry and trade have played an important part. The fact that our industrial health service is voluntary and based on a mutual tripartite agreement, and that it accords with modern concepts of 
hygiene and social medicine, has laid the foundation for general recognition and support, and has hastened the expansion of the programme. It seems that a better solution to the financial and professional administrative problems could not have been found, and that we were most fortunate in arriving at this solution at the very start.

Not only private firms but also municipal and state concerns have participated in the plan. Industrial health services have also been adopted by a number of business concerns, banks, etc., and not only by manufacturing plants.

That the employers are on the whole satisfied with the plan is evident from their support. Most employers regard the industrial health service as a valuable asset and consider the expenses involved to be a good investment.

The attitude of the workers and personnel is best demonstrated by the fact that there is almost $100 \%$ attendance at the medical examinations, which are entirely voluntary, and that the workers themselves to a large extent apply to the management for the introduction of the industrial health service in their plant.

Our physicians have shown great interest in the industrial health service. Approximately 600 physicians have completed a training course for works physicians, and the Norwegian Industrial Medical Association now has a membership of 260 active works physicians. The works health service supplements and fits well into the pattern of our medical organization, and good cooperation exists between the works physician and the private practitioners. Most works physicians work on a parttime basis from one to 24 hours per week. Only three are doing full-time in-plant service.

The industrial physicians have generally been well qualified for their work, both with regard to preventive medical examinations and health guidance. It might be assumed that the so-called family doctors would be those best qualified for preventive health work, because of their knowledge of the previous state of health of the employees and their home environment. Our experiences show that the majority of the employees attend the medical examinations at the works health department. The same amount of cooperation would hardly result if these examinations were to be carried out by the family doctor.

By our present system the works physician quickly adjusts himself to the demands of prophylactic medical work, and will get acquainted with the workers, the plant, and the work through his inplant service. This knowledge of the occupational milieu and problems is as important as the knowledge of the home environment. Also, the first interview and the subsequent consultations, as well as the sickness absence reports, will soon enable the works physician to form a true picture of the previous and present state of health of the workers and their families.

\section{Values and Costs}

The question of the value of industrial health control cannot be definitely answered because so many factors are imponderable. We shall for a long time have to rely on personal impressions more than on statistical data. However, it seems quite clear to those with some years of experience in industrial health work that industrial health care is an important factor in the efforts towards improved physical and mental health in the general public.

A few results of the health work in Norwegian industry may serve to throw some light on the question. The discovery of disease is only a part of industrial health care, but still an important one. The question most often asked is how efficient is an industrial health service for diagnostic and therapeutic purposes. Many works physicians have followed our request to report the various diseases, defects, and anomalies discovered by routine examinations at the plant and in how many instances treatment had not been given previously. The results for the years 1948 and 1949 are shown in Table 1.

The various groups of diseases as a cause of absence among men and women, and manual and clerical workers in 1949 are shown in Table 2. The figures represent the percentage distribution of absence of more than three days' duration according to various diseases.

Exact figures of costs cannot be given, because the expenses vary according to the size, needs, and financial resources of the various industries. It is calculated that the average cost per head per year amounts to 20 to 30 Norwegian kroner (20-30s.).

A primary aim is to discover hitherto unknown cases of diseases among the workers examined. A second objective is to assist the workers needing medical attention in securing early and correct treatment, and to spread information about medical advances, and thus establish a popular confidence in the modern methods and facilities available. We frequently observe in our practice that the popular conception of medical therapeutic facilities is outmoded sometimes by 20 to 30 years. It is our privilege and our duty to inform the population about these possibilities. The third aim is to study the incidence and distribution of various diseases and anomalies among the workers. Our industrial 
TABLE 1

DISEASES, DEFECTS, AND ANOMALIES DETECTED ON ROUTINE INDUSTRIAL MEDICAL EXAMINATION

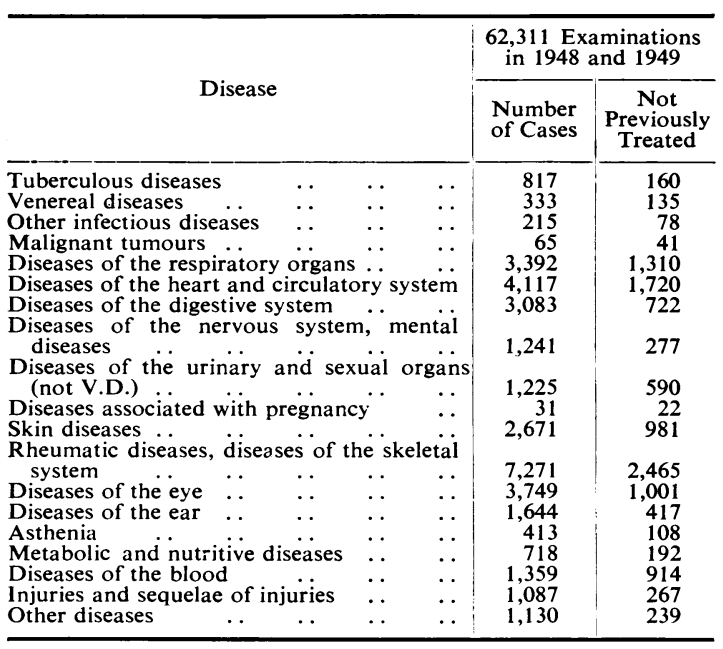

Hypertension, defined as a systolic pressure above $160 \mathrm{~mm}$., was found in $1.4 \%$ of male workers under 40 years of age, in $12 \%$ between the ages of 40 and 59 years, and in $18 \%$ above 60 years. The corresponding figures for women were $0 \cdot 7,17$, and $42 \%$ respectively.

A diastolic pressure above $100 \mathrm{~mm}$. was found in $2 \cdot 5,12$, and $27 \%$ of male workers in the corresponding groups, and among women in $0 \cdot 5,13$, and $33 \%$ respectively.

Anaemia, defined as a haemoglobin content below $90 \%$ for men and below $80 \%$ for women, was found in $3.4 \%$ of the men and $4 \%$ of women workers. Pathologically increased sedimentation rates, above $20 \mathrm{~mm}$. for men and $40 \mathrm{~mm}$. for women, were found in $4 \%$ of the men and $11 \%$ of women workers.

A positive Meinicke reaction was found in $1.8 \%$ of all workers in 1948 and $0.8 \%$ in 1949 .

health service has been organized to provide for all these aspects of health care.

Tables 1 and 2 illustrate the incidence of diseases detected on routine industrial examination. Considering the fact that those examined are presumably healthy individuals, these figures clearly indicate the value of these examinations. This is further confirmed by the fact that between 10 and $15 \%$ of the workers examined are found to be in need of medical treatment for some ailment.

However, attempts to evaluate these services in their economic relationship are futile. The values represented cannot be counted in money. What does it mean to the individual concerned, to the plant, and to society that the unknown presence of a disease is revealed so that the disease may be treated in time? According to what economic scale should attempts be made to evaluate, for example, the detection of 350 cases of tuberculosis, 250 cases of syphilis, and 110 cases of cancer, per year among the 165,000 workers included in the industrial health service?
In addition to these diseases many other major and minor ailments are found.

The detection of disease, however, is only one aspect of industrial health care, or what might be called the negative aspect. The positive aspect is the health information programme and prophylactic measures. The value of the health guidance programme lies in the possibilities of making the modern therapeutic methods known to the public and the establishment of an intimate contact between the physician and the workers. In times when mental and nervous disturbances seem to become more and more prevalent, it is of essential value for the workers to have a physician to whom they can confide their troubles and fears. This cannot be evaluated in terms of financial gain. The same applies to the prophylactic measures such as vaccinations, relaxation exercises, physical exercise and massage, as well as the personal influence of the physician with regard to the preservation of good health.

The regular medical examination in the various firms will also be of great value by showing the incidence and influence of various diseases among the adult population.

The work of the physician to promote better hygienic conditions in the plant also merits attention. The function of the physician as the active hygienist of the plant was not as much stressed

TABLE 2

DISEASES CAUSING ABSENCE IN MANUAL AND CLERICAL WORKERS

\begin{tabular}{|c|c|c|c|c|c|}
\hline \multirow{2}{*}{ Disease } & & \multicolumn{2}{|c|}{ Men } & \multicolumn{2}{|c|}{ Women } \\
\hline & & $\begin{array}{l}\text { Manual } \\
\text { Workers }\end{array}$ & $\begin{array}{l}\text { Clerical } \\
\text { Workers }\end{array}$ & $\begin{array}{l}\text { Manual } \\
\text { Workers }\end{array}$ & $\begin{array}{l}\text { Clerical } \\
\text { Workers }\end{array}$ \\
\hline $\begin{array}{l}\text { Tuberculous diseases } \ldots \\
\text { Venereal diseases } \ldots \\
\text { Other infectious diseases } \\
\text { Malignant tumours } \\
\text { Diseases of the respira- }\end{array}$ & $\begin{array}{l}\cdots \\
\cdots\end{array}$ & $\begin{array}{l}7 \cdot 5 \\
0 \cdot 4 \\
2 \cdot 3 \\
1 \cdot 0\end{array}$ & $\begin{array}{l}9 \cdot 2 \\
0 \cdot 07 \\
1 \cdot 2 \\
1 \cdot 3\end{array}$ & $\begin{array}{l}3 \cdot 4 \\
0 \cdot 1 \\
2 \cdot 7 \\
0 \cdot 9\end{array}$ & $\begin{array}{l}4 \cdot 8 \\
0 \\
0 \cdot 9 \\
1 \cdot 3\end{array}$ \\
\hline $\begin{array}{l}\text { tory organs } \ddot{1} \\
\text { Diseases of the heart and }\end{array}$ & $\cdots$ & $18 \cdot 7$ & $24 \cdot 6$ & $17 \cdot 4$ & $18 \cdot 7$ \\
\hline $\begin{array}{l}\text { circulatory system } \\
\text { Diseases of the digestive }\end{array}$ & $\cdots$ & $4 \cdot 8$ & $6 \cdot 7$ & $3 \cdot 5$ & $3 \cdot 6$ \\
\hline Diseases of the nervous & . & $10 \cdot 4$ & $9 \cdot 7$ & $7 \cdot 1$ & $5 \cdot 9$ \\
\hline $\begin{array}{l}\text { system, mental diseases } \\
\text { Diseases of the urinary } \\
\text { and sexual organs (not }\end{array}$ & & $5 \cdot 5$ & $9 \cdot 0$ & $8 \cdot 0$ & $10 \cdot 5$ \\
\hline $\begin{array}{l}\text { V.D.) . } \\
\text { Diseases associated with }\end{array}$ & $\cdots$ & $2 \cdot 4$ & $3 \cdot 3$ & $6 \cdot 4$ & $7 \cdot 2$ \\
\hline $\begin{array}{ccc}\text { pregnancy } & \ldots & \ldots \\
\text { Skin diseases } & \ldots & \ldots\end{array}$ & $\begin{array}{l}\cdots \\
\cdots\end{array}$ & $\overline{2 \cdot 2}$ & $\overline{1 \cdot 2}$ & $\begin{array}{l}2 \cdot 8 \\
3 \cdot 2\end{array}$ & $\begin{array}{l}1 \cdot 5 \\
1 \cdot 5\end{array}$ \\
\hline $\begin{array}{l}\text { Rheumatic diseases, dis- } \\
\text { eases of the skeletal }\end{array}$ & & & & & 1.3 \\
\hline $\begin{array}{lll}\text { system } \ldots & \ldots & \ldots\end{array}$ & . & 18 . & $17 \cdot 0$ & $23 \cdot 0$ & 31.4 \\
\hline $\begin{array}{l}\text { Diseases of the eye } \\
\text { Diseases of the ear }\end{array}$ & $\cdots$ & $1 \cdot$ & $\begin{array}{l}1 \cdot 1 \\
1 \cdot 2\end{array}$ & & 0.4 \\
\hline $\begin{array}{l}\text { Diseases of the ear } \quad \ldots \\
\text { Asthenia } \ldots\end{array}$ & $\because$ & 0.3 & $0 \cdot 1$ & 0.9 & $0 \cdot 6$ \\
\hline $\begin{array}{l}\text { Asthenia } \\
\text { Metabolic and nutritive } \\
\text { diseases }\end{array}$ & $\cdots$ & & 0.1 & $2 \cdot 3$ & $1 \cdot 0$ \\
\hline $\begin{array}{l}\text { diseases } \\
\text { Diseases of the blood } \cdots \\
\text { Injuries and sequelae of }\end{array}$ & $\ddot{x}$ & $\begin{array}{l}0 \cdot 4 \\
0 \cdot 2\end{array}$ & $\begin{array}{l}0 \cdot 2 \\
0 \cdot 1\end{array}$ & $\begin{array}{l}0 \cdot 2 \\
2 \cdot 6\end{array}$ & $\begin{array}{l}0.6 \\
1.0\end{array}$ \\
\hline $\begin{array}{ccc}\text { Injuries and sequelae of } \\
\text { injuries } & \ldots & \ldots \\
\text { Other diseases } & \ldots & \ldots\end{array}$ & $\begin{array}{l}\cdots \\
\cdots\end{array}$ & $\begin{array}{r}17 \cdot 7 \\
5 \cdot 8\end{array}$ & $\begin{array}{r}12 \cdot 1 \\
2 \cdot 0\end{array}$ & $\begin{array}{l}8 \cdot 2 \\
6 \cdot 4\end{array}$ & $\begin{array}{l}6 \cdot 6 \\
2 \cdot 5\end{array}$ \\
\hline
\end{tabular}


previously as it is today. Accordingly, the work of the earlier physicians was almost entirely confined to health control. This, however, was a necessary and natural step in the development. During the initial years of their work, the works physicians had to concentrate on their medical duties alone and become acquainted with the workers and the various manufacturing processes at the plant.

A marked change has taken place during recent years, as the physicians are now more actively engaged in promoting hygienic conditions.

It might be argued whether a works physician receiving payment from the firm can give efficient service in the field of occupational hygiene. On rare occasions the management have actually created difficulties. Those employers who decide to appoint an industrial health physician are fully informed about the various aspects of the industrial health service as agreed upon, including occupational hygiene. Initiative in this field on the part of the works physician is expected and any proposals from him in this connexion will usually receive positive consideration. Experiences seem to indicate that there does not exist any serious obstacle of this nature.

It might also be discussed whether or not works physicians, most of whom are private practitioners, specialists, and public medical officers without special training in occupational hygiene, possess the necessary qualifications for preventing occupational diseases and promoting occupational hygiene. Special courses for physicians and medical students have been given, but these do not give adequate and complete preparation in the field. The reason why we cannot yet offer complete training in occupational hygiene is that we do not have an institute of occupational hygiene which fulfils our present needs.

In spite of these defects, a number of works physicians have performed very admirable hygienic sanitation work in their respective plants. Many investigations have been initiated to solve special problems and a number of various scientific research projects have been completed and published. At the larger industrial concerns with laboratories the physician may carry out such investigations at the plant with the assistance of the engineers. Most works physicians, however, must rely on assistance from the National Labour inspectorate and our Institute of Occupational Health and the out-patient department of occupational diseases in Oslo.

In addition to investigations, such as determinations of the contents of poisonous substances in the blood, urine, and air, and dust analyses, the work includes regular inspections of lavatories, lunch- rooms, wardrobes, baths and showers, lighting, chairs, temperature in the plant, and, most important, order and cleanliness. Complaints from the workers with respect to hygienic deficiencies are immediately investigated. This is an important part of the duties of the works physician. The work of physicians, nurses, and welfare workers in nearly 600 firms adds up to a considerable contribution to industrial health care.

\section{Industrial and Public Health Services}

The major part of preventive health care in Norway is carried out by the local boards of health and by the public medical officers under the administrative authority of the Directorate of Health. These various organs of the public health services are connected with industrial health care in various ways.

Full cooperation has existed with the Director General of Public Health, who is usually the nominating party in the employment of works physicians.

Many of the public medical officers take part in hygienic work as part-time works physicians. The Directorate of Health works towards the objective of creating a full-time office for public health work so that those engaged can fully devote their time to this type of work, by combining public and industrial health duties. Within a four-months course for public health officers three weeks' instruction in industrial medicine and hygiene is given.

Cooperation has also been established between the works physicians and the local boards of health, especially in the field of tuberculosis control. In certain locations where health centres have been established the industrial medical examinations may be carried out at the centre.

At first it seems to be a logical idea that the industrial health service should belong to the work and administrative authority of the boards of health. As the industrial health service is completely supported by the industrial firms themselves, this transfer is not practicable. It would, however, be desirable to establish a closer contact between the boards of health and the industrial health service. This might be accomplished by making the reports, submitted by the works physicians to the Board of Industrial Health Service, available also to the local board of health. The board of health might also take the initiative in promoting this contact by coordinating their investigations with those included in the industrial health work by furnishing material for health information suggesting the form of the health cards, and by contributing toward technical equipment and service.

That the industrial health service is administered 
by the independent Board of the Industrial Health Service is both a weakness and a strength. The weakness consists in the absence of laws and the resulting dependence on mutual tripartite agreement. Another weak point is the lack of coordination with other public health work, which accounts for some overlapping or duplication of certain projects. The strength lies in the voluntary basis and the flexibility of policies which facilitates changes as necessitated by medical and social developments.

\section{The State Labour and Factory Inspection Board and the Industrial Health Service}

In accordance with our law on labour and factory inspection, a local industrial supervisory committee shall be established in each municipality to supervise the hygienic conditions in industrial and other concerns within the district. The central authority is vested in the State Labour and Factory Inspection Board, which from the very start of the industrial health service has cooperated with the works physicians. This is partly due to the fact that physicians from the State Labour and Factory Inspection Board have taken part in formulating the policies for the industrial health service. There has never existed any noticeable friction between the works physicians and this board, or any overlapping in their work worth mentioning. The works physicians help the board in much the same way as the board gives practical and scientific assistance to the works physicians. The survey of occupational diseases throughout the entire country resulting from the work of the works physicians is only one example of the kind of assistance which these can give to the inspectorate.

If our labour and factory inspection had been expanded with the services of the additional number of physicians, chemists, engineers, and inspectors who could effectively serve all firms throughout our country, it might possibly have taken over all the investigations of occupational hygiene necessary in industry. However, it could not have replaced the individual hygienic work of the works physicians. The State Labour and Factory Inspection Board has therefore encouraged the firms to introduce the industrial health service as a means of improving working conditions. Our main concern is not, therefore, that of favouring one at the expense of the other, but of continued cooperation in the belief that further development of both the industrial health service and the industrial supervisory organization is that best serving the needs of occupational hygiene and public health.

Still closer cooperation might, however, be desirable, for example, by sharing reports about hygienic conditions and sickness absences with the Labour and Factory Inspection Board, and by a joint inspection in firms with a works physician.

\section{Conclusion}

This form of industrial health service has sprung out of the special conditions in Norway, and has enabled us to establish an industrial health service without danger of weakening the medical services as a whole. Needless to say, any lack of physicians would have prevented the creation of this service, and our system is therefore not advisable in a country with a shortage of physicians.

Another distinguishing feature in this system is that the geographical extension of our country and the difficult communications in many places have necessitated the delegation of the preventive health work to the private physicians and only to a smaller extent to health centres and institutes.

A third feature is that our industrial supervision is not so far developed and efficient as in some other countries, and cannot offer the same service as similar organizations in more densely populated countries, even if it had been further developed.

Our experiences so far indicate that the system we have chosen will survive. This does not mean that our industrial health service will continue in its present form. On the contrary, we shall endeavour to improve it as desirable and necessary on the basis of changes in the medical and social views and according to experience.

However, the two basic principles upon which the industrial health service is founded, namely, health control of the employees and hygienic work in the plant, have been sound and efficient.

That we have recognized the same principles in the industrial health services of other countries seems to confirm their value. 